OPEN ACCESS

Edited by:

Mehdi Razzaghi-Abyaneh,

Pasteur Institute of Iran, Iran

Reviewed by:

Yew-Min Tzeng,

National Taitung University, Taiwan

Vahid Khalaj,

Pasteur Institute of Iran, Iran

*Correspondence:

Zheng-Hong Xu

zhenghxu@jiangnan.edu.cn

Specialty section

This article was submitted to

Food Microbiology,

a section of the journal

Frontiers in Microbiology

Received: 10 June 2017 Accepted: 06 October 2017

Published: 23 October 2017

Citation:

LuZ-M, Zhu Q, Li H-X, Geng Y,

Shi J-S and Xu Z-H (2017) Vanillin Promotes the Germination of Antrodia

camphorata Arthroconidia through

PKA and MAPK Signaling Pathways.

Front. Microbiol. 8:2048

doi: $10.3389 /$ fmicb.2017.02048

\section{Vanillin Promotes the Germination of Antrodia camphorata Arthroconidia through PKA and MAPK Signaling Pathways}

\author{
Zhen-Ming $L u^{1}$, Qing Zhu ${ }^{1}$, Hua-Xiang $L i^{1}$, Yan Geng ${ }^{1}$, Jin-Song Shi ${ }^{1}$ and \\ Zheng-Hong $\mathrm{Xu}^{1,2 *}$
}

${ }^{1}$ National Engineering Laboratory for Cereal Fermentation Technology, School of Pharmaceutical Science, Key Laboratory of Industrial Biotechnology of Ministry of Education, Jiangnan University, Wuxi, China, ${ }^{2}$ Tianjin Key Laboratory for Industrial Biological Systems and Bioprocessing Engineering, Tianjin Institute of Industrial Biotechnology, Chinese Academy of Sciences, Tianjin, China

Wild fruiting bodies of medicinal mushroom Antrodia camphorata are only found on the endemic species bull camphor tree, Cinnamomum kanehirae, in Taiwan. Despite the evident importance of the host components in promoting the growth of $A$. camphorata, insights into the underlying mechanisms are still lacking. Here, we first evaluated effects of the compounds from C. kanehirai, C. camphora, and A. camphorata, and their structural analogs on the germination rate of $A$. camphorata arthroconidia. Among the 54 tested compounds, vanillin (4-hydroxy-3-methoxybenzaldehyde) was determined as the optimum germination promoter, while o-vanillin and 1-octen-3-ol as major negative regulators of arthroconidia germination. Second, the protein patterns of arthroconidia after $24 \mathrm{~h}$ of incubation in the presence or absence of vanillin were compared via isobaric tags for relative and absolute quantitation (iTRAQ)-based proteomics. Via bioinformatic analysis, it was found that 61 proteins might relate to the germination of arthroconidia, in which 16 proteins might involve in two potential protein kinase A (PKA) and mitogen-activated protein kinase (MAPK) signaling pathways in the vanillin-promoted germination of $A$. camphorata arthroconidia. Last, the mRNA expression levels of the 16 germination-related genes in the potential PKA and MAPK signaling pathways were analyzed by quantitative real time PCR. Together, our results are beneficial for the elucidation of molecular mechanisms underlying the germination of $A$. camphorata arthroconidia.

Keywords: Antrodia camphorata, arthroconidia, germination, proteomics, vanillin

\section{IMPORTANCE}

Wood-decay fungus Antrodia camphorata shows natural host specificity to Cinnamomum kanehirae. We hypothesize that host factors might possess stimulatory activity on the arthroconidial germination and mycelial growth of A. camphorata. In this study, we screened optimal germination regulators from host- and A. camphorata-originated compounds and their structural analogs. The germination-promoting factors might be used for efficient artificial cultivation of A. camphorata. Meanwhile, isobaric tags for relative and absolute quantitation (iTRAQ)-based analysis of the 
proteomes of A camphorata arthroconidia revealed two potential protein kinase A (PKA) and mitogen-activated protein kinase (MAPK) mediated signaling pathways which might relate to the germination under vanillin or 1-octen-3-ol treatments. The mRNA expression levels of 16 germination-regulating genes in the potential PKA and MAPK pathways were analyzed by RT-qPCR. Our results provide useful information for elucidating molecular mechanisms underlying $A$. camphorata development.

\section{INTRODUCTION}

Antrodia camphorata (syn. Antrodia cinnamomea, Taiwanofungus camphoratus) is a rare medicinal mushroom of the family Polyporaceae. It exhibits various biological functions, such as anti-oxidation, anti-inflammatory, antitumor, anti-cancer, liver protection, anti-hepatitis B virus, and vaso-relaxation (Geethangili and Tzeng, 2011; Lu et al., 2013). More than 80 bioactive compounds, including triterpenoids, polysaccharides, antrodins A-E, benzenoids, and antroquinonollike compounds, have been identified from A. camphorata (Ao et al., 2009).

Fruiting bodies of $A$. camphorata are in great market demand today, but they are extremely expensive due to their host specificity, rarity in nature, and complex cultivation. To satisfy the large consumption demand, submerged fermentation (SmF) has been adopted as an efficient artificial cultivation way to industrial production of $A$. camphorata (Wu et al., 2006). Many researchers focused on the nutritional and environmental factors affecting the SmF of $A$. camphorata mycelia and the accumulation of bioactive metabolites. In our previous study, we reported that $A$. camphorata sporulates asexually (arthroconidia) at the later stage of $\mathrm{SmF}$ under appropriate environmental conditions (Geng et al., 2013). The arthroconidia from fermentation broth could be used as the inoculum for next batch SmF, and the arthroconidia-based inoculation had several advantages including simplicity, good controllability, and high efficiency (shorten the operation time of traditional mycelium-based inoculation from 240 to 168 h; Lu et al., 2014a). Furthermore, a repeated batch fermentation process based on the asexual reproduction of $A$. camphorata (arthroconidia $\rightarrow$ filamentous mycelia $\rightarrow$ mycelial pellets $\rightarrow$ arthroconidia) was developed for the efficient and economic production of bioactive metabolites ( $\mathrm{Li}$ et al., 2015). Although, the genomes of A. camphorata isolates were recently deciphered using nextgeneration sequencing techniques (Lu et al., 2014), the molecular mechanisms underlying the arthroconidial germination and formation remain poorly characterized.

Wild fruiting bodies of $A$. camphorata were only found on the heartwood of endemic species bull camphor tree, C. kanehirae Hayata, in Taiwan. It is hypothesized that host factors in the $C$. kanehirae might possess stimulatory activity on the arthroconidial germination and mycelial growth of A. camphorata. Previous studies have revealed that the growth of A. camphorata could be promoted in the presence of water-soluble wood extracts from the host (C. kanehirae) and four host-related species (C. micranthum, C. osmophloeum,
C. camphora, and C. kotoense) (Shen et al., 2004). Four wood essential oils from C. kanehirae, C. camphora, Cunninghamia konishii, and Chamaecyparis formosensis also promoted the growth of A. camphorata (Chang and Wang, 2008). Alpha-terpineol, geraniol, citronellol, L-linalool, eugenol, and D-camphor in essential oil of $C$. kanehirae promoted the growth of A. camphorata mycelia ( $\mathrm{Wu}, 2002)$. Alpha-terpineol could also stimulate the synthesis of triterpenoids in the mycelia of A. camphorata ( $\mathrm{Lu}$ et al., 2014b). It is of interest to evaluate stimulatory effects of compounds from $C$. kanehirae on the germination of $A$. camphorata arthroconidia. Otherwise, fruiting bodies and mycelia of $A$. camphorata contain numerous volatile compounds and possess a highly odiferous aroma (see Table S1) (Chen et al., 2007; Liu et al., 2008; Shao et al., 2008; Lu et al., 2011; Xia et al., 2011). Although it is well-known that volatile compounds can act as signaling molecules, nothing is known about their involvement in A. camphorata lifecycle.

In this study, effects of the compounds from C. kanehira, C. camphor and A. camphorata, and their structural analogs on the germination of $A$. camphorata arthroconidia were evaluated. Then, differential expressed proteins relating to the arthroconidial germination of A. camphorata in the presence and absence of germination regulator were identified via iTRAQ-based proteomic analysis. Potential genes relating to the germination of $A$. camphorata arthroconidia were identified by bioinformatic analysis. Last, the mRNA expression level of potential germination-related genes were validated by quantitative real time PCR (RT-qPCR).

\section{MATERIALS AND METHODS}

\section{Chemicals and Materials}

All the candidate compounds from C. kanehira, C. camphor, and fruiting bodies and mycelia of A. camphorata (Figure 1A) were purchased from Sinopharm Chemical Reagent Co., Ltd. (Shanghai, China). Yeast extract was provided by Oxoid Ltd. (Basingstoke, Hampshire, UK). Other nutrients used in this study were purchased from Sinopharm Chemical Reagent Co., Ltd. (Shanghai, China). The purities of all the substrates were $\geq 98 \%$.

\section{Strain and Cultivation}

Antrodia camphorata ATCC 200183 was obtained from the American Type Culture Collection (USA), and maintained on potato dextrose agar (PDA) slants, and stored at $4^{\circ} \mathrm{C}$ after incubated for 14 days at $26^{\circ} \mathrm{C}$ (Lu et al., 2014a).

\section{Preparation of Arthroconidial Inoculum}

To prepare fresh arthroconidia, the mycelia of $A$. camphorata on the PDA slants were transferred to 500-mL shaking flasks containing $100 \mathrm{~mL}$ germination medium (GM), which was composed of $2.0 \mathrm{~g}$ glucose, $0.2 \mathrm{~g}$ yeast extract, $0.15 \mathrm{~g} \mathrm{MgSO}_{4}$, and $0.3 \mathrm{~g} \mathrm{KH} \mathrm{KH}_{4}$, with the initial $\mathrm{pH}$ of 4.5 . The mycelia were incubated at $26^{\circ} \mathrm{C}$ for 20 days by shaking at 150 $\mathrm{rpm}$. The fermentation broth was filtered through four layers of sterile gauze and three layers of lens paper, then the filtrate was centrifugated at $6,000 \mathrm{~g}$ for $5 \mathrm{~min}$ at $26^{\circ} \mathrm{C}$. The arthroconidia sediment was washed twice with $10 \mathrm{~mL}$ distilled 


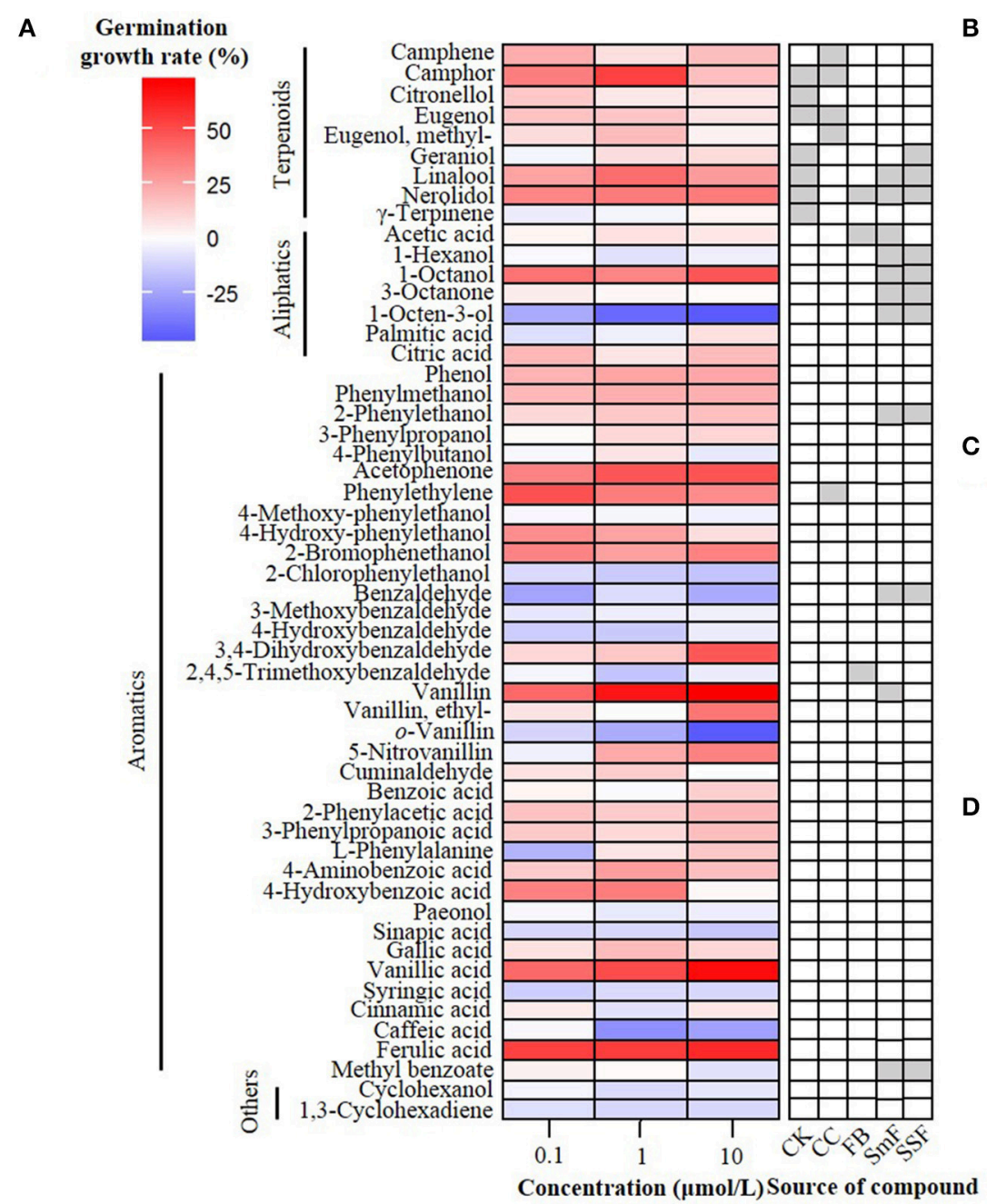

B
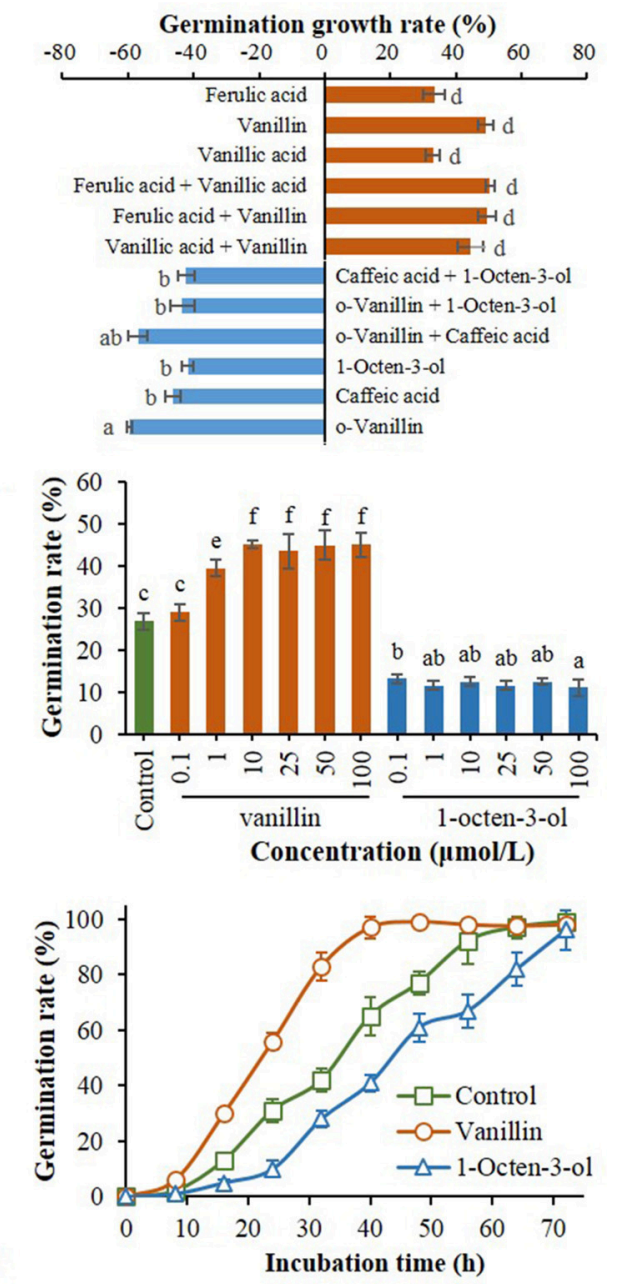

FIGURE 1 | Effect of compounds from C. kanehira, C. camphor, and A. camphorata as well as their analogs on the germination of A. camphorata arthroconidia. (A) Heatmap showing germination growth rate of the arthroconidia after $24 \mathrm{~h}$ of incubation with candidate compounds in 96-well microplates. CK, Cinnamomum kanehirae; CC, C. camphora; FB, fruiting bodies of A. camphorata; SmF, submerged fermentation of A. camphorata; SSF, solid-state fermentation of $A$. camphorata; (B) Effects of positive and negative regulators $(10 \mu \mathrm{mol} / \mathrm{L})$ and their synergistic effects on the germination of arthroconidia after $24 \mathrm{~h}$ of incubation in $500-\mathrm{mL}$ shaking flasks; (C) Germination rate of vanillin- and 1-octen-3-ol-treated arthroconidia after $24 \mathrm{~h}$ of incubation in 500 -mL shaking flasks through concentration scale (0.1-100 $\mu \mathrm{mol} / \mathrm{L})$. (D) Germination process of the arthroconidia treated with vanillin $(25 \mu \mathrm{mol} / \mathrm{L})$ or 1 -octen-3-ol $(25 \mu \mathrm{mol} / \mathrm{L})$ in $500-\mathrm{mL}$ shaking flasks. Columns marked with different letters possess values of significantly difference $(P<0.05)$.

$0.9 \% \mathrm{NaCl}$ solution, and diluted with basal germination medium (BGM), which was composed of $20 \mathrm{~g} / \mathrm{L}$ of glucose, $10 \mathrm{~g} / \mathrm{L}$ of valine, $1.5 \mathrm{~g} / \mathrm{L}$ of $\mathrm{MgSO}_{4}$, and $3 \mathrm{~g} / \mathrm{L}$ of $\mathrm{KH}_{2} \mathrm{PO}_{4}$, with the initial $\mathrm{pH}$ of 4.5 . The concentration of arthroconidia was calculated by counting with a hemocytometer under a light microscope. The arthroconidial suspension with a desired concentration was then used as the inoculum for subsequent experiments.

\section{Screening Germination Regulator of Arthroconidia in 96-Well Plate}

The source of the compounds for the initial screening is shown in Table S1. Stock solutions of the candidate compounds (30 $\mathrm{mmol} / \mathrm{L}$ ) were prepared with $95 \%$ ethanol. Fresh arthroconidia of $A$. camphorata $\left(1 \times 10^{5}\right.$ spore $\left./ \mathrm{mL}\right)$ were incubated in the BGM in the presence or absence of candidate compounds $(0.1,1$, and $10 \mu \mathrm{mol} / \mathrm{L}$ ) in 96-well microplates. An equal volume of $95 \%$ ethanol (final concentration, $0.2 \mu \mathrm{mol} / \mathrm{L}$ ) was added to BGM in the control group. The arthroconidia in the 96-well microplates were incubated at $26^{\circ} \mathrm{C}$ for $48 \mathrm{~h}$ by shaking at $250 \mathrm{rpm}$ on an INFORS Multitron incubator shaker (INFORS HT, Swissland). The germination process of arthroconidia was observed by light microscopy (Nikon TE2000S, Japan) in five randomly selected areas in each well. At least 150 arthroconidia were analyzed for each well with image J software, and the arthroconidia was deemed germinated when the total length was at least twice the original length of arthroconidia. Germination growth rate (GGR) of arthroconidia was calculated according to the following 
equation: GGR $=[(\%$ germination rate in compound-treated group $/ \%$ germination rate in control group) -1$] \times 100$.

\section{Validation of Germination-Regulating Effect in Shaking Flask}

Effects of three positive regulators (vanillin, vanillic acid, and ferulic acid) and negative regulators (1-octen-3-ol, $o$-vanillin, and caffeic acid) and their synergistic effects on the germination of A. camphorata arthroconidia were validated at a concentration of $10 \mu \mathrm{mol} / \mathrm{L}$ in 500-mL Erlenmeyer flasks. The inoculum size of arthroconidia was $10^{7}$ spores $/ \mathrm{mL}$. An equal volume of absolute ethanol was added to BGM in the control group.

Effects of different concentrations of vanillin and 1-octen-3ol $(0.1,1.0,10,25,50$, and $100 \mu \mathrm{mol} / \mathrm{L})$ on the germination were evaluated in 500-mL Erlenmeyer flasks containing $100 \mathrm{~mL}$ of BGM. The cultivation of arthroconidia was conducted on a rotary shaker at $26^{\circ} \mathrm{C}$ for $24 \mathrm{~h}$ by shaking at $150 \mathrm{rpm}$. An equal volume of $95 \%$ ethanol was added to BGM in the control group. Meanwhile, germination process of arthroconidia in the presence of vanillin $(25 \mu \mathrm{mol} / \mathrm{L})$, or 1-octen-3-ol $(25 \mu \mathrm{mol} / \mathrm{L})$ was observed in a $500-\mathrm{mL}$ shaking flask. Determination of arthroconidial germination rate in shaking-flask cultures were performed according to previous description.

\section{Extraction of Total Proteins}

Fresh arthroconidia of $A$. camphorata were inoculated into a $1000-\mathrm{mL}$ shaking flask containing $400 \mathrm{~mL}$ of BGM in the presence of vanillin $(25 \mu \mathrm{mol} / \mathrm{L})$ or 1-octen-3-ol $(25 \mu \mathrm{mol} / \mathrm{L})$. The inoculum size of arthroconidia was $1 \times 10^{7}$ spore $/ \mathrm{mL}$. The shaking-flask culture was performed at $26^{\circ} \mathrm{C}$ for $24 \mathrm{~h}$ by shaking at $150 \mathrm{rpm}$. Arthroconidia in the fermentation broth were collected by centrifugation at $6,000 \mathrm{~g}$ for $5 \mathrm{~min}$ at $26^{\circ} \mathrm{C}$. The arthroconidia sediment was washed twice with $50 \mathrm{~mL}$ of distilled $0.9 \% \mathrm{NaCl}$ solution, freshly frozen in liquid $\mathrm{N}_{2}$, and stored at $-80^{\circ} \mathrm{C}$ until further use.

Approximately $100 \mathrm{mg}$ of arthroconidia samples from five biological replicates were mixed and ground in liquid nitrogen to a fine powder, which was then transferred to a $50-\mathrm{mL}$ tube and suspended in $30 \mathrm{~mL}$ of ice-cold acetone containing $10 \%$ trichloroacetic acid, $1 \mathrm{mM}$ of phenylmethanesulfonyl fluoride (PMSF), and $3 \mathrm{~g} / \mathrm{L}$ of dithiothreitol (DTT). After treatment at $-20^{\circ} \mathrm{C}$ for $12 \mathrm{~h}$, the suspension was centrifugated at $11,000 \mathrm{~g}$ for $20 \mathrm{~min}$ at $4^{\circ} \mathrm{C}$. The resulting pellet was resuspended in $30 \mathrm{~mL}$ of ice-cold acetone containing $3 \mathrm{~g} / \mathrm{L} \mathrm{DTT}$, kept at $-20^{\circ} \mathrm{C}$ for $2 \mathrm{~h}$, and centrifugated at $4^{\circ} \mathrm{C}$ again $(11,000 \mathrm{rpm}, 20 \mathrm{~min})$. The supernatant was discarded and the pellet was washed twice with cold acetone. Then the precipitate was washed twice with $90 \%$ cold acetone. After air-drying, the pellet was dissolved in $1 \mathrm{~mL}$ of protein extraction buffer (Sangon Biotech, Shanghai, China) followed by centrifugation at $11,000 \mathrm{~g}$ for $20 \mathrm{~min}$ at $4^{\circ} \mathrm{C}$. The protein content of the arthroconidia extract was determined using the modified Bradford protein assay kit with bovine serum albumin as the standard.

\section{Protein Identification by iTRAQ}

The freeze-dried protein powders in each sample were resuspended in triethylammonium bicarbonate after reductive alkylation. Then, proteins were digested by trypsin with enzyme to substrate ratio of $1: 50(\mathrm{w} / \mathrm{w})$ at $37^{\circ} \mathrm{C}$ for $15 \mathrm{~h}$. Furthermore, the digested peptides were labeled with iTRAQ Reagent Kit (Applied Biosystems, Foster city, CA, USA), using 114-, 115-, 116-, and 117-tag for the culture samples, respectively. The iTRAQ-labeled samples were analyzed by Majorbio Bio-pharm Technology Co., Ltd (Shanghai, China), with a NanoAquity UPLC system connected to Q Exactive hybrid quadrupoleOrbitrap mass spectrometer (Thermo Fisher Scientific, USA). A local protein database including the information of germinationrelated proteins collected from references and the Genbank (https://www.ncbi.nlm.nih.gov/genbank/) was established (see Table S2). The amino acid sequences of identified proteins from iTRAQ were matched to the local protein database, and the GO (http://geneontology.org/) and KEGG (http://www.genome.jp/ $\mathrm{kegg} /$ ) databases to search protein candidates which might be involved in the germination of $A$. camphorata arthroconidia (see Figure S1). Growth rate of the expression level of specific gene was calculated according to the following equation: [(\% expression level of gene in compound-treated group $/ \%$ expression level in control (or ethanol-treated) group)-1] $\times$ 100. The mass spectrometry proteomics data have been deposited to the ProteomeXchange Consortium via the PRIDE (Vizcaíno et al., 2016) partner repository with the dataset identifier PXD007266.

\section{Quantitative RT-qPCR}

To verify the results from iTRAQ proteomic analysis, we used RT-qPCR to quantify the mRNA expression levels of the 16 genes under the treatments of vanillin $(25 \mu \mathrm{mol} / \mathrm{L})$ and 1-octen-3-ol $(25 \mu \mathrm{mol} / \mathrm{L})$. Fresh arthroconidia of $A$. camphorata $\left(1 \times 10^{7}\right.$ spore $/ \mathrm{mL}$ ) were inoculated into in a $1,000-\mathrm{mL}$ shaking flask containing $400 \mathrm{~mL}$ of $\mathrm{BGM}$ in the presence of vanillin (25 $\mu \mathrm{mol} / \mathrm{L})$ or 1 -octen-3-ol $(25 \mu \mathrm{mol} / \mathrm{L})$. No ethanol was added in the BGM. The cultivation of arthroconidia was conducted on a rotary shaker at $26^{\circ} \mathrm{C}$ for $24 \mathrm{~h}$ by shaking at $150 \mathrm{rpm}$. Arthroconidia in the fermentation broth were collected by centrifugation at $6,000 \mathrm{~g}$ for $5 \mathrm{~min}$ at $26^{\circ} \mathrm{C}$. The arthroconidia sediment was washed twice with $50 \mathrm{~mL}$ of distilled $0.9 \% \mathrm{NaCl}$ solution.

Total RNA of A. camphorata arthroconidia was extracted with UNIQ-10 Column Trizol Total RNA Isolation Kit (Sangon Biotech, Shanghai, China) according to the instruction of manufacturer, and RNA was quantified by spectrophotometer technique at $260 \mathrm{~nm}$. To obtain cDNA pools from the total RNA, reverse transcription was performed using M-MuLV First Strand cDNA Synthesis Kit (Sangon Biotech, Shanghai, China). RT-qPCR was performed using SYBR Green mix detection. Primers for RT-qPCR (see Table S3) were designed using Beacon Designer software 7.0. The 18S rRNA gene of A. camphorata was used as the internal standard. Relative expression level of gene was quantified using a real time PCR system (Applied Biosystems 7500 ) based on the $2^{-\Delta \Delta C t}$ method.

\section{Statistical Analyses}

The experiments of germination regulator screening and RT-qPCR analysis were carried out at least thrice, each time with 
at least three replicates. The data are presented as the mean \pm standard deviation (SD) and the groups were accompanied by one-way analysis of variance (ANOVA). Duncans' test was performed for determining the significance. Differences at $P<0.05$ were considered statistically significant.

\section{RESULTS}

\section{Screening of Germination Regulator}

A total of 54 candidate compounds including 9 terpenoids, 7 aliphatics, and 36 aromatics were screened in 96-well plate (Figure 1A). Among these compounds, vanillin, vanillic acid, and ferulic acid showed optimal germination-promoting activities (GGR > 55\%) in a dose-dependent manner, with the GGRs of $71.51,68.28$, and $59.60 \%$ at the dosage of $10 \mu \mathrm{mol} / \mathrm{L}$ after $24 \mathrm{~h}$ of incubation (Figure 1A). o-Vanillin, 1-octen-3-ol, caffeic acid were the main negative regulators of arthroconidia germination, with the GGRs of $-45.83,-46.61$, and $-25.81 \%$ at the dosage of $10 \mu \mathrm{mol} / \mathrm{L}$, respectively (Figure 1A). After $24 \mathrm{~h}$ of incubation, there was no significant synergistic effect between any two positive regulators (vanillin, vanillic acid, and ferulic acid) or negative regulators (1-octen-3-ol, $o$-vanillin, and caffeic acid) on the germination of $A$. camphorata arthroconidia $(P>0.05$; Figure 1B).

Regulatory effects of vanillin and 1-octen-3-ol on the arthroconidial germination were validated in $500-\mathrm{mL}$ shaking flasks (Figure 1C). As the concentration of vanillin increased from 0.1 to $10 \mu \mathrm{mol} / \mathrm{L}$, the germination rate of $A$. camphorata arthroconidia significantly increased $(P<0.05$; Figure 1C). In all the tested concentrations $(0.1-10 \mu \mathrm{mol} / \mathrm{L}), 1$-octen-3-ol could significantly decrease the germination rate of $A$. camphorata arthroconidia as compared with that of the control group $(P<0.05)$.

\section{iTRAQ-Based Proteomic Analysis}

Protein patterns of non-germinated $(0 \mathrm{~h})$, ethanol-treated $(24 \mathrm{~h})$, vanillin-treated $(24 \mathrm{~h})$, and 1-octen-3-ol-treated $(24 \mathrm{~h})$ arthroconidia were analyzed by iTRAQ-based quantitative approach. A total of 3109 proteins were identified from A. camphorata arthroconidia (see Table S4). The amino acid sequences of identified proteins were annotated with the GO and KEGG databases, and the annotation results are listed in Tables S5, S6. Meanwhile, the protein dataset was matched to the local database of germination-related protein, and 61 proteins were found to be related to the germination of fungal spores (see Table S7).

Growth rates of the expression levels of 61 germinationrelated proteins in A. camphorata arthroconidia are shown in Figure 2. As compared with the ethanol-treated arthroconidia (24 h), 25 potential germination-related proteins (SepA, SMC, GapA, Fkh2, PkaA, Erg6, Sip2, Cas2, Sho1, Cpa1, Ric8, Erg12, Rgf2, NosA, FphA, Sak1, Rac1, Cdc42, CpcB, AtfA, RfxA, Ypk1, ICL1, Cat-1, and Fad5) showed opposite expression levels between the vanillin-treated $(24 \mathrm{~h})$ and the 1-octen-3-oltreated $(24 \mathrm{~h})$ groups (Figure 2). As compared with the control $(0 \mathrm{~h})$, there were 29,39 , and 21 up-regulated proteins (GGR $>10 \%)$ in the ethanol-treated $(24 \mathrm{~h})$, vanillin-treated $(24 \mathrm{~h})$, and 1-octen-3-ol-treated ( $24 \mathrm{~h})$ arthroconidia, while 16, 11, and 12 proteins were down-regulated, respectively (GGR $<10 \%$; Figure 2).

\section{Potential Germination-Related Signaling Pathway}

Among 61 germination-related proteins in A. camphorata arthroconida, there were 16 proteins ( $\mathrm{SfaD}, \mathrm{GanB}$, Ric8, CyaA, PkaR, PkaA, Cre1, Bmh1, GapA, Ras2, RasA, Rac1, Cdc42, PakA, $\mathrm{Cmk}$, and Pmr1) potentially involved in two signaling pathways, namely PKA and MAPK pathways. Among these 16 proteins, 6 proteins (RasA, sfaD, GanB, Cdc42, Rac1, PakA, and PkaA) were also annotated in Chemokine signaling pathway (Ko04062) and Focal adhesion pathway (Ko04510) via KEGG pathway analysis (see Figure S2). Based on published references, we proposed two potential PKA and MAPK signaling pathways which might relate to the vanillin-promoted germination of $A$. camphorata arthroconidia (Figure 3).

\section{Analysis of mRNA Expression Level by RT-qPCR}

The mRNA expression levels of 16 genes in the potential PKA and MAPK signaling pathways were studied (Figure 4). The mRNA expression levels of 4 genes $(b m h 1, r i c 8, r a c 1$, and $p k a R)$ in the control $(0 \mathrm{~h})$ and the arthroconidia $(24 \mathrm{~h})$ were not detectable by RT-qPCR, whereas they significantly increased after $48-72 \mathrm{~h}$ of incubation (data not shown). pakA and ganB could only be detected in the control group $(0 \mathrm{~h})$ (Figure 4). As compared with the control $(0 \mathrm{~h})$, the expression levels of all the genes except cyaA decreased significantly in the control $(24 \mathrm{~h})(P<0.05)$ (Figure 4). After the treatment of vanillin $(24 \mathrm{~h})$, the expression levels of gap $A, \operatorname{ras} 2, c m k 1, p k a A, c r e 1$, and ras $A$ significantly increased, while that of $c d c 42$ significantly decreased, as compared with those of the control group $(24 \mathrm{~h})(P<0.05)$. Noteworthy, cre 1 and pkaA showed 33.0- and 6.6-fold increases in the vanillintreated arthroconidia $(24 \mathrm{~h})$ as compared with those of the control group $(24 \mathrm{~h})$. After the treatment of 1-octen-3-ol, the expression level of $c d c 42$ decreased significantly as compared with that of the control group $(24 \mathrm{~h})(P<0.05)$.

\section{DISCUSSION}

Wood-decay fungus $A$. camphorata shows natural host specificity to $C$. kanehirae. In wild forest, fruiting bodies of $A$. camphorata are usually found on the inner wall of fallen C. kanehirae (Ao et al., 2009). It is hypothesized that the content of essential oil in decaying C. kanehirae supports the growth of A. camphorata. In this study, most terpenoids from $C$. kanehirae, including camphene, camphor, citronellol, eugenol, geraniol, linalool, and nerolidol, showed germination-promoting activities at the concentration of $0.1-10 \mu \mathrm{mol} / \mathrm{L}$ (Figure 1A). These terpenoids widely exist in the essential oils of Cinnamomum species, and they usually have potent antimicrobial activities at high concentrations (Kalemba et al., 2012). Although more than 58 volatile compounds have been reported in C. kaehirae and C. camphora (Wu et al., 2003; Shen et al., 2004; Hsu et al., 


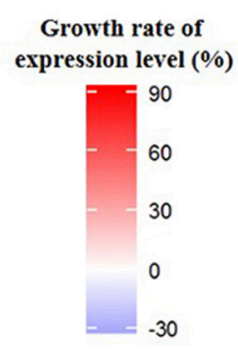

Growth rate of
pression level (\%)

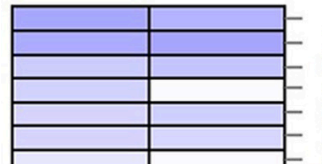

Atg8

RasA

Cpp1

Mas5

PakA

GerO

Cdc48

Bmp1

Myosin 1

Ubc1

PkaR

$\mathrm{SfaD}$

VelB

Snf1

Cmk1

Pkh1

HK2

Ras2

Bmh1

Fpk1

Skp1

Chi4

Tps

Pmr1

Cot-1

GanB

Bem 2

Bem2 2

ConF

ChiA

LaeA

CyaA

Fad9

Cat-1

ICL1

Ypk1

RIXA

AtfA

$\mathrm{CpcB}$

$\mathrm{Cdc4}_{\mathrm{Racl}}$

Rak1

FphA

NosA

Rgf2

Erg12

Ric8

Cas 2

Sip2

Erg6

Fkh2

Fkh2

SMC

SepA

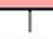

Van/Eth

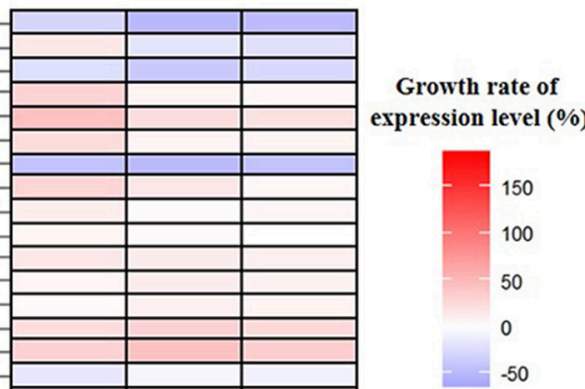

$-50$

FIGURE 2 | Growth rate of the expression levels of 61 germination-related proteins in A. camphorata arthroconidia by iTRAQ-based proteomic analysis. Growth rate of the expression level of specific gene was calculated according to the following equation: [(\% expression level of gene in compound-treated group/\% expression level in control (or ethanol-treated) group)-1] × 100. Ctl, control group of non-germinated arthroconida; Eth, ethanol-treated arthroconidia after $24 \mathrm{~h}$ of incubation; Van, vanillin-treated arthroconidia after $24 \mathrm{~h}$ of incubation; Oct, 1-octen-3-ol-treated arthroconidia after $24 \mathrm{~h}$ of incubation.

2006; Chang and Wang, 2008), only 8 host-related volatiles were tested in this study. Thus, it is of interest in future study to evaluate more volatile and non-volatile compounds originated from the host, and to elucidate the host-fungus interaction between $C$. kanehirae and A. camphorata.

Antrodia camphorata sporulates a large number of arthroconidia $\left(>10^{8}\right.$ spores $\left./ \mathrm{mL}\right)$ at the end of $\mathrm{SmF}$, which is a phenomenon rarely reported in basidiomycetous fungi. The crowding effect is a widely existed phenomenon that fungal germination is inhibited at high spore concentrations (Gillot et al., 2016). Otherwise, we hypothesized that the volatiles produced by $A$. camphorata in SmF might inhibit the arthroconidial germination. In this study, $o$-vanillin, 1-octen-3-ol, caffeic acid, benzaldehyde were determined as the major germination inhibitors to $A$. camphorata arthroconidia (Figure 1A). Hereinto, 1-octen-3-ol, namely mushroom alcohol, is a major mushroom-like flavor in A. camphorata fermentation broth (relative content, 21\%) (Lu et al., 2011). This $\mathrm{C}_{8}$ aliphatic compound has been reported as a self-inhibitor of spore germination in many kinds of mushrooms (Chitarra, 2003). 1-Octanol was reported as a self-inhibitor of spore germination in Penicillium camemberti (Gillot et al., 2016), but it functioned as a germination promoter of $A$. camphorata arthroconidia in this study (Figure 1A). The aromatic compounds showed various 


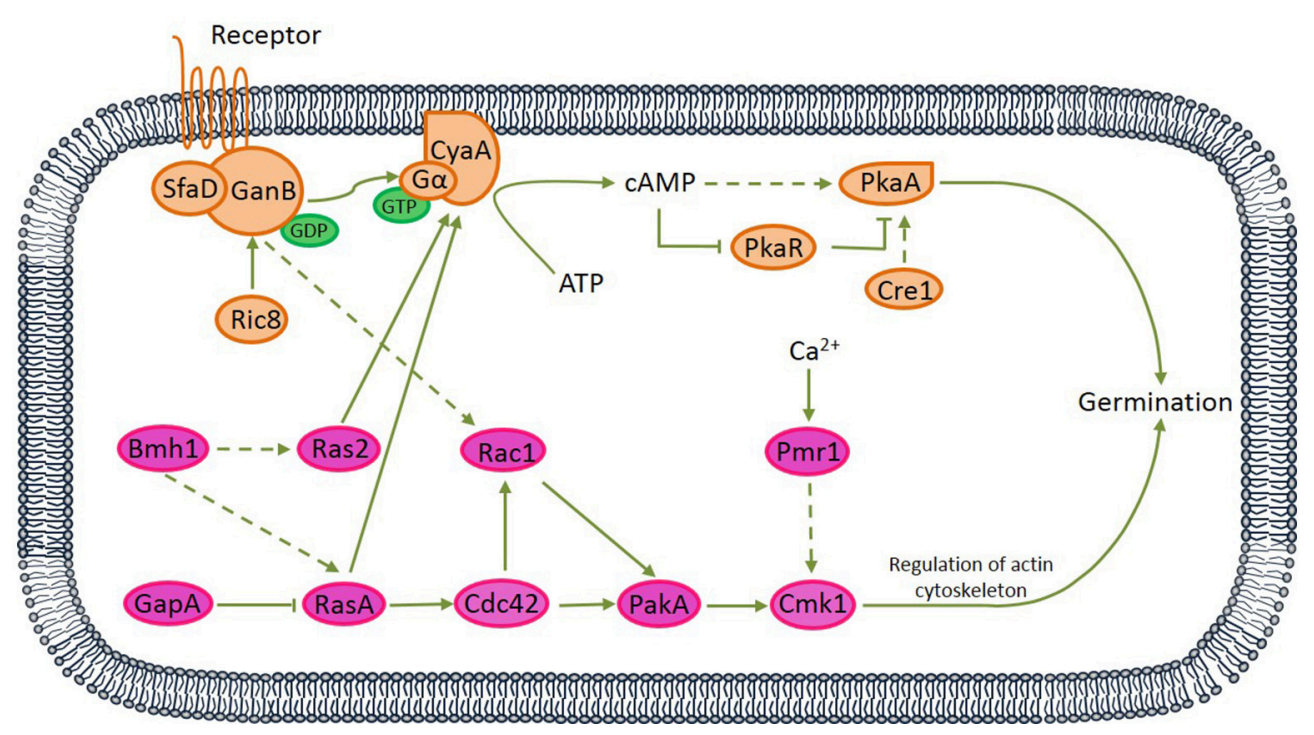

FIGURE 3 | Proposed protein kinase A (PKA) and mitogen-activated protein kinase (MAPK) signaling pathways relating to the germination of $A$. camphorata arthroconidia. Both G protein-coupled receptor (seven transmembrane receptor) and non-receptor RIC8 (guanine nucleotide exchange factor) might be capable of activating $\mathrm{GanB}(\alpha)-\mathrm{SfaD}(\beta)$ dimer, thereby might lead to GDP-GTP exchange on the G $\alpha$ protein. Active G $\alpha$-GTP further might trigger cAMP/PKA signaling by separating from CyaA subunit and activating adenylate cyclase, which might be responsible for cAMP synthesis. cAMP binding to the regulatory subunit of PKA might cause its dissociation from the catalytic subunit (PKAc)

effects on the germination of A. camphorata arthroconidia. For instance, vanillin (4-hydroxy-3-methoxybenzaldehyde) and vanillic acid (4-hydroxy-3-methoxybenzoic acid) showed potent germination-promoting activity, while $o$-vanillin (2-hydroxy3-methoxybenzaldehyde), caffeic acid, and benzaldehyde and its derivatives functioned as negative regulators (Figure 1A). Otherwise, the arthroconidial germination-promoting activities of 2-phenylethanol and its structural analogs (phenol, 3phenylpropanol, and 4-phenylbutanol) decreased as the chain length of alcohol on benzene ring increased (Figure 1A). As such, further studies are needed to explore the structure-function relationship between these chemicals and arthroconidial development.

Vanillin is a type of phenolic compound that can be released during the pre-treatment of lignocellulosic materials. Vanillin usually plays an inhibitory role in the growth of many kinds of microorganisms, such as yeast species, Aspergillus species, Escherichia coli, Lactobacillus plantarum, Listeria innocua, and Corynebacterium glutamicum (Chen et al., 2016). Vanillin can suppress translation by affecting the ribosome assembly process, causing accumulation of cytoplasmic mRNP granules and processing bodies (Iwaki et al., 2013). Furthermore, vanillin induces the accumulation of reactive oxygen species and mitochondrial fragmentation in Saccharomyces cerevisiae (Nguyen et al., 2017). In vanillin-resistant Saccharomyces cerevisiae strains, many reductases and dehydrogenases might contribute to the strain growth and vanillin reduction (Shen et al., 2014; Wang et al., 2016). In our study, we used the iTRAQ-based proteomic approach to explore potential molecular mechanisms underlying the germination of vanillin-treated A. camphorata arthroconidia. A 3109 proteins-containing picture showing the protein pattern of $A$. camphorata arthroconidia was obtained (see Table S4). It stands to reason that the annotation results of amino acid sequences in this study might be affected by the capacity and quality of the local germination-related protein database (see Table S2). For example, it is well known that heterotrimeric $\mathrm{G}$ protein $\operatorname{GanB}(\alpha)-\operatorname{SfaD}(\beta)-\mathrm{GpgA}(\gamma)$ signaling is essential for normal asexual and sexual development and hyphal growth in many filamentous fungus (Lafon et al., 2005; Li et al., 2007; Eaton et al., 2012). However, a $\operatorname{Gan} B(\alpha)-\operatorname{SfaD}(\beta)$ dimer was annotated in the protein dataset. It is suggested that the $\operatorname{GpgA}(\gamma)$ might be absent in the A. camphorata or the amino acid sequence of $\operatorname{GpgA}(\gamma)$ got a low matching score. To this point, as the information in protein database increase, the functional assignment of amino acid sequences in this study will be more accurate.

Via bioinformatics analysis, 61 germination-related proteins were identified (see Table S7), and 16 proteins distributed in the PKA and MAPK pathways. Based on published references, we proposed two signaling transduction pathways relating to the vanillin-promoted germination of A. camphorata arthroconidia (Figure 3). In the PKA-mediated signaling pathway, both $G$ protein-coupled receptor (seven transmembrane receptor) and non-receptor guanine nucleotide exchange factor Ric8 might be capable of activating $\operatorname{GanB}(\alpha)-\operatorname{SfaD}(\beta)$ dimer, thereby might lead to GDP-GTP exchange on the G $\alpha$ protein (Lafon et al., 2005; Li et al., 2007; Eaton et al., 2012). Active G $\alpha$-GTP likely triggered cAMP/PKA signaling by separating from CyaA subunit and activating adenylate cyclase, which might be responsible for cAMP synthesis. cAMP binding to the regulatory subunit of PKA might cause its dissociation from the catalytic subunit (PkaA) (Fillinger et al., 2002). In the MAPK-mediated signaling pathway, 


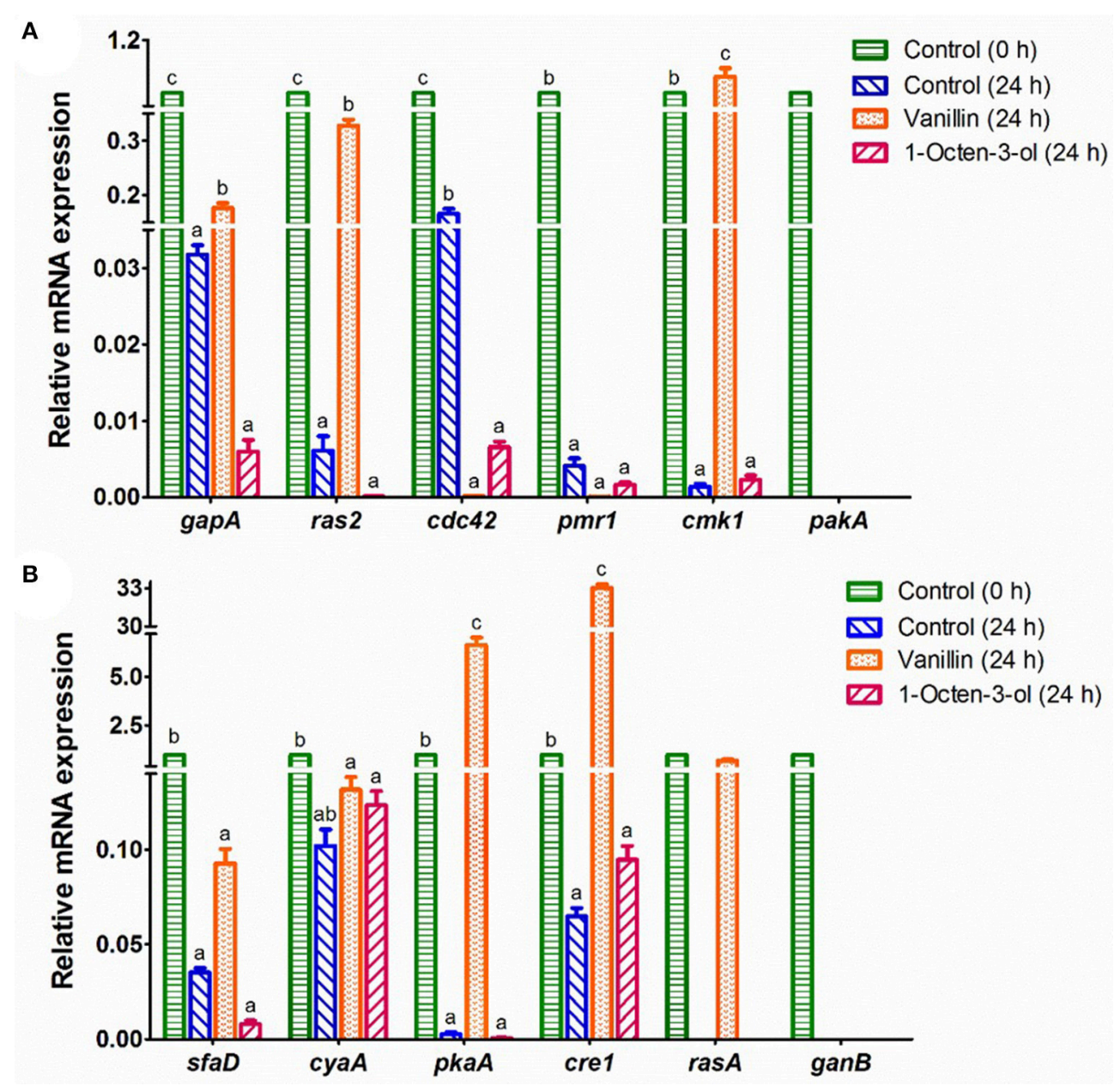

FIGURE 4 | RT-qPCR analysis of the mRNA expression of genes which might relate to the germination of $A$. camphorata arthroconidia. (A) gapA, ras2, cdc42, pmr1, cmk1, and pakA; (B) sfaD, cyaA, pkaA, cre1, rasA, and ganB. The 18S rRNA gene of $A$. camphorata was used as an internal reference, and non-germinated arthroconidia $(\mathrm{O} h)$ was used as control. Data were presented as mean $\pm S D$. Inter-group statistical differences of the relative expression level of a specific gene were evaluated with Tukey's multiple-range test. $P<0.05$ were considered statistically significant. Columns marked with different letters in a treatment group possess values of significantly difference $(P<0.05)$.

Bmh1 might activate RasA, and Ras2 (Liu et al., 2015), while Ras GTPase-activating protein GapA likely down-regulated RasA (Harispe et al., 2008). RasA and Ras2 are molecular switches which are active in a GTP- and inactive in a GDP-bound state. RasA might regulate the small Rho GTPase Cdc42 (Mahlert et al., 2006; Kokkelink et al., 2011), thereby likely activated p21-activated kinase PakA (Boyce and Andrianopoulos, 2007). PakA, together with Golgi P-type $\mathrm{Ca}^{2+}$-ATPase Pmr1, positively regulated Cmk1 (Wang et al., 2013). There interactions existed between the PKA and MAPK pathways. RasA and Ras2 might play antagonistic roles in regulating cellular cAMP level by acting on adenylate cyclase (Zhu et al., 2009; Harata and Kubo, 2014), and GanB might regulate Rac1 (Figure S2A).

The mRNA transcription levels of 12 genes in the potential PKA and MAPK pathways were analyzed by RTqPCR (Figure 4). Besides these genes, there are other 45 germination-related proteins identified by iTRAQ analysis (see Table 57). For example, Ecm33 is one of several glycosylphosphatidylinositol (GPI)-anchored proteins. This protein is known to be involved in fungal cell wall integrity, conidiation, and multi-stress tolerance (Chen et al., 2014). Thus, further studies are needed to validate the effect of these proteins on the germination of A. camphorata arthroconidia. Otherwise, the gene expression levels might change significantly during the germination of $A$. camphorata arthroconidia. In this study, we only analyzed the differences of gene expression levels after $24 \mathrm{~h}$ of germination regulator treatments. It is possible that the gene expressions between the treatment group and the control group would show more obvious differences at other time in the germination process. Further studies are needed to reveal the gene expression dynamics through germination. Furthermore, genetic evidence for these 61 germination-related proteins should be collected in further study. Alternatively, potential specific protein antagonist may be explored for validating the functions of the proteins in the signaling pathway proteins. In a recent study, genetic operations 
of A. camphorata including protoplast transformation and homologous recombination have been performed to construct biosynthesis pathway of benzenoid-derivatives ( $\mathrm{Yu}$ et al., 2015). These genetic tools are helpful to elucidate molecular mechanisms underlying the development of A. camphorata.

To conclude, we found that vanillin was an optimum germination promoter, while $o$-vanillin, and 1-octen-3-ol as the major negative regulators of arthroconidia germination. Furthermore, a 3,109 proteins-containing picture showing the protein patterns of $A$. camphorata arthroconidia in the presence of germination regulators was obtained by the iTRAQbased proteomic analysis. Via bioinformatic analysis, it was found that 61 proteins might relate to the germination of arthroconidia, in which 16 proteins ( $\mathrm{SfaD}, \mathrm{GanB}$, Ric8, CyaA, PkaR, PkaA, Cre1, Bmh1, GapA, Ras2, RasA, Rac1, Cdc42, PakA, Cmk1, and Pmr1) might involve in two potential PKA and MAPK signaling pathways in vanillin-promoted germination of A. camphorata arthroconidia. The mRNA expression levels of 16 germination-regulating genes in the potential PKA and MAPK pathways were analyzed by RT-qPCR.

\section{AUTHOR CONTRIBUTIONS}

ZL, ZX, and JS conceived and designed the experiments. ZL, YG analyzed the data and wrote the paper. QZ and HL performed the experiments and analyzed the data. All authors reviewed the manuscript.

\section{REFERENCES}

Ao, Z. H., Xu, Z. H., Lu, Z. M., Xu, H. Y., Zhang, X. M., and Dou, W. F. (2009). Niuchangchih (Antrodia camphorata) and its potential in treating liver diseases. J. Ethnopharmacol. 121, 194-212. doi: 10.1016/j.jep.2008.10.039

Boyce, K. J., and Andrianopoulos, A. (2007). A p21-activated kinase is required for conidial germination in Penicillium marneffei. PLoS Pathog. 3, 1556-1569. doi: 10.1371/journal.ppat.0030162

Chang, T. T., and Wang, W. R. (2008). The role of four essential oils on mycelial growth and basidiomatal formation of Antrodia cinnamomea. Taiwan J. For. Sci. 23, 105-110.

Chen, C. C., Chyau, C. C., and Hseu, T. H. (2007). Production of a COX-2 inhibitor, 2,4,5-trimethoxybenzaldehyde, with submerged cultured Antrodia camphorata. Lett. Appl. Microbiol. 44, 387-392. doi: 10.1111/j.1472-765X.2006.02087.x

Chen, C., Pan, J., Yang, X., Guo, C., Ding, W., Si, M., et al. (2016). Global transcriptomic analysis of the response of Corynebacterium glutamicum to vanillin. PLoS ONE 11:e0164955. doi: 10.1371/journal.pone.0164955

Chen, Y., Zhu, J., Ying, S. H., and Feng, M. G. (2014). The GPI-anchored protein Ecm33 is vital for coniation, cell wall integrity, and multi-stress tolerance of two filamentous entomopathogens but not for virulence. Appl. Microbiol. Biotechnol. 98, 5517-5529. doi: 10.1007/s00253-014-5577-y

Chitarra, G. S. (2003). Germination Inhibitors of Fungal Spores: Identification and Mode of Action. Ph.D. thesis. Wageningen University.

Eaton, C., Cabrera, I. E., Servin, J. A., Wright, S. J., Cox, M. P., and Borkovich, K. A. (2012). The guanine nucleotide exchange factor RIC8 regulates conidial germination through $\mathrm{G} \alpha$ proteins in Neurospora crassa. PLoS ONE 10:e48026. doi: 10.1371/journal.pone.0048026

Fillinger, S., Chaveroche, M. K., Shimizu, K., Keller, N., and d'Enfert, C. (2002). cAMP and ras signalling independently control spore germination in the filamentous fungus Aspergillus nidulans. Mol. Microbiol. 44, 1001-1016. doi: 10.1046/j.1365-2958.2002.02933.x

\section{FUNDING}

This work was supported by the grant from National Natural Science Foundation of China (No. 31401931).

\section{SUPPLEMENTARY MATERIAL}

The Supplementary Material for this article can be found online at: https://www.frontiersin.org/articles/10.3389/fmicb. 2017.02048/full\#supplementary-material

Figure S1 | A schematic diagram of the bioinformatics analysis for iTRAQ.

Figure S2 | Distribution of 16 germination-related proteins in KEGG pathway. (A) Chemokine signaling pathway (Ko04062). Six proteins including Cdc42, Rac (Rac1), PAK1 (PakA), Ras (RasA), GB (SfaD), and PKA (PkaA) were related to the germination of $A$. camphorata arthroconidia. (B) Focal adhesion pathway (Ko04510). Three proteins including Cdc42, Rac (Rac1), and PAK (PakA) were related to the germination of $A$. camphorata arthroconidia.

Table S1 | Reported volatile compounds in C. kaehirae, C. camphora, and A. camphorata.

Table S2 | Local database of germination-related proteins.

Table S3 | Primers used for RT-qPCR.

Table S4 | Proteins in A. camphorata arthroconidia identified by iTRAQ.

Table S5 | Annotation of the proteins from ITRAQ with the GO database.

Table S6 | Annotation of the proteins from ITRAQ with the KEGG database.

Table S7 | Germination-related proteins in A. camphorata arthroconidia identified by ITRAQ.

Geethangili, M., and Tzeng, Y. M. (2011). Review of pharmacological effects of Antrodia camphorata and its bioactive compounds. Evid. Based Complement. Alternat. Med. 2011:212641. doi: 10.1093/ecam/nep108

Geng, Y., He, Z., Lu, Z. M., Xu, H. Y., Xu, G. H., Shi, J. S., et al. (2013). Antrodia camphorata ATCC 200183 sporulates asexually in submerged culture. Appl. Microbiol. Biot. 97, 2851-2858. doi: 10.1007/s00253-012-4513-2

Gillot, G., Decourcelle, N., Dauer, G., Barbier, G., Coton, E., Delmail, D., et al. (2016). 1-Octanol, a self-inhibitor of spore germination in Penicillium camemberti. Food Microbiol. 57, 1-7. doi: 10.1016/j.fm.2015.12.008

Harata, K., and Kubo, Y. (2014). Ras GTPase activating protein Colral is involved in infection-related morphogenesis by regulating cAMP and MAPK signaling pathways through CoRas2 in Colletotrichum orbiculare. PLoS ONE 9:e109045. doi: 10.1371/journal.pone.0109045

Harispe, L., Portela, C., Scazzocchio, C., Peñalva, M. A., and Gorfinkiel, L. (2008). Ras GTPase-activating protein regulation of actin cytoskeleton and hyphal polarity in Aspergillus nidulans. Eukaryotic Cell 7, 141-153. doi: 10.1128/EC.00346-07

Hsu, F. L., Chou, C. J., Chang, Y. C., Chang, T. T., and Lu, M. K. (2006). Promotion of hyphal growth and underlying chemical changes in Antrodia camphorata by host factors from Cinnamomum camphora. Int. J. Food Microbiol. 106, 32-38. doi: 10.1016/j.ijfoodmicro.2005.07.003

Iwaki, A., Ohnuki, S., Suga, Y., Izawa, S., and Ohya, Y. (2013). Vanillin inhibits translation and induces messenger ribonucleoprotein (mRNP) granule formation in Saccharomyces cerevisiae: application and validation of high-content, image-based profiling. PLoS ONE 8:e61748. doi: 10.1371/journal.pone.0061748

Kalemba, D., Matla, M., and Smetek, A. (2012). "Antimicrobial activities of essential oils," in Dietary Phytochemicals and Microbes, ed A. K. Patra (Dordrecht: Springer Press), 157-183. doi: 10.1007/978-94-007-3926-0

Kokkelink, L., Minz, A., Al-Masri, M., Giesbert, S., Barakat, R., Sharon, A., et al. (2011). The small GTPase BcCdc42 affects nuclear division, germination and 
virulence of the gray mold fungus Botrytis cinerea. Fungal Genet. Biol. 48, 1012-1019. doi: 10.1016/j.fgb.2011.07.007

Lafon, A., Seo, J. A., Han, K. H., Yu, J. H., and d'Enfert, C. (2005). The heterotrimeric G-protein $\operatorname{GanB}(\alpha)-\operatorname{SfaD}(\beta)-\mathrm{GpgA}(\gamma)$ is a carbon source sensor involved in early cAMP-dependent germination in Aspergillus nidulans. Genetics 171, 71-80. doi: 10.1534/genetics.105.040584

Li, H. X., Lu, Z. M., Geng, Y., Gong, J. S., Zhang, X. J., Shi, J. S., et al. (2015). Efficient production of bioactive metabolites from Antrodia camphorata ATCC 200183 by asexual reproduction-based repeated batch fermentation. Bioresour. Technol. 194, 334-343. doi: 10.1016/j.biortech.2015.06.144

Li, L., Wright, S. J., Krystofova, S., Park, G., and Borkovich, K. A. (2007). Heterotrimeric $\mathrm{G}$ protein signaling in filamentous fungi. Annu. Rev. Microbiol. 61, 423-452. doi: 10.1146/annurev.micro.61.080706.093432

Liu, H., Jia, W., Zhang, J. S., and Pan, Y. J. (2008). GC-MS and GColfactometry analysis of aroma compounds extracted from culture fluids of Antrodia camphorata. World J. Microbiol. Biotechnol. 24, 1599-1602. doi: 10.1007/s11274-007-9614-1

Liu, Q., Li, J. G., Ying, S. H., Wang, J. J., Sun, W. L., Tian, C. G., et al. (2015). Unveiling equal importance of two 14-3-3 proteins for morphogenesis, conidiation, stress tolerance and virulence of an insect pathogen. Environ. Microbiol. 17, 1444-1462. doi: 10.1111/1462-2920.12634

Lu, M. C., El-Shazly, M., Wu, T. Y., Du, Y. C., Chang, T. T., Chen, C. F., et al. (2013). Recent research and development of Antrodia cinnamomea. Pharmacol. Ther. 139, 124-156. doi: 10.1016/j.pharmthera.2013.04.001

Lu, M. Y., Fan, W. L., Wang, W. F., Chen, T., Tang, Y. C., Chu, F. H., et al. (2014). Genomic and transcriptomic analyses of the medicinal fungus Antrodia cinnamomea for its metabolite biosynthesis and sexual development. Proc. Natl. Acad. Sci. U.S.A. 111, E4743-E4752. doi: 10.1073/pnas.1417570111

Lu, Z. M., He, Z., Li, H. X., Gong, J. S., Geng, Y., Xu, H. Y., et al. (2014a). Modified arthroconidial inoculation method for the efficient fermentation of Antrodia camphorata ATCC 200183. Biochem. Eng. J. 87, 41-49. doi: 10.1016/j.bej.2014.03.020

Lu, Z. M., Geng, Y., Li, H. X., Sun, Q., Shi, J. S., and Xu, Z. H. (2014b). Alpha-terpineol promotes triterpenoid production of Antrodia cinnamomea in submerged culture. FEMS Microbiol. Lett. 358, 36-43. doi: 10.1111/1574-6968.12545

Lu, Z. M., Tao, W. Y., Xu, H. Y., Lim, J., Zhang, X. M., Wang, L. P., et al. (2011). Analysis of volatile compounds of Antrodia camphorata in submerged culture using headspace solid-phase microextraction. Food Chem. 127, 662-668. doi: 10.1016/j.foodchem.2010.12.111

Mahlert, M., Leveleki, L., Hlubek, A., Sandrock, B., and Bolker, M. (2006). Rac1 and $\mathrm{Cdc} 42$ regulate hyphal growth and cytokinesis in the dimorphic fungus Ustilago maydis. Mol. Microbiol. 59, 567-578. doi: 10.1111/j.1365-2958.2005.04952.x

Nguyen, T. T. M., Iwaki, A., and Izawa, S. (2017). The ADH7 promoter of Saccharomyces cerevisiae is vanillin-inducible and enables mRNA translation under severe vanillin stress. Front. Microbiol. 6:1390. doi: $10.3389 /$ fmicb.2015.01390

Shao, Y. Y., Chen, C. C., Wang, H. Y., Chiu, H. L., Hseu, T. H., and Kuo, Y. H. (2008). Chemical constituents of Antrodia camphorata submerged whole broth. Nat. Prod. Res. 22, 1151-1157. doi: 10.1080/14786410601132410

Shen, Y. C., Chou, C. J., Wang, Y. H., Chen, C. F., Chou, Y. C., and $\mathrm{Lu}, \mathrm{M}$. K. (2004). Anti-inflammatory activity of the extracts from mycelia of Antrodia camphorata cultured with water-soluble fractions from five different Cinnamomum species. FEMS Microbiol. Lett. 231, 137-143. doi: 10.1016/S0378-1097(03)00953-4

Shen, Y., Li, H., Wang, X., Zhang, X., Hou, J., Wang, L., et al. (2014). High vanillin tolerance of an evolved Saccharomyces cerevisiae strain owing to its enhanced vanillin reduction and antioxidative capacity. J. Ind. Microbiol. Biotechnol. 41, 1637-1645. doi: 10.1007/s10295-014-1515-3

Vizcaíno, J. A., Csordas, A., del-Toro, N., Dianes, J. A., Griss, J., Lavidas, I., et al. (2016). 2016 update of the PRIDE database and related tools. Nucleic Acids Res. 44, D447-D456. doi: 10.1093/nar/gkw880

Wang, J., Zhou, G., Ying, S. H., and Feng, M. G. (2013). P-type calcium ATPase functions as a core regulator of Beauveria bassiana growth, conidiation and responses to multiple stressful stimuli through cross-talk with signalling networks. Environ. Microbiol. 15, 967-979. doi: 10.1111/1462-2920.12044

Wang, X., Liang, Z., Hou, J., Bao, X., and Shen, Y. (2016). Identification and functional evaluation of the reductase and dehydrogenases from Saccharomyces cerevisiae involved in vanillin resistance. BMC Biotechnol. 16:31. doi: 10.1186/s12896-016-0264-y

Wu, H., Pan, C. L., Yao, Y. C., Chang, S. S., Li, S. L., and Wu, T. F. (2006). Proteomic analysis of the effect of Antrodia camphorata extract on human lung cancer A549 cell. Proteomics 6, 826-835. doi: 10.1002/pmic.200401341

Wu, S. Y. (2002). Effects of the Extracts from Cinnamomum Kanehirae on the Mycelial Growth of Antrodia Camphorata. Master thesis, National Taiwan University, Taiwan.

Wu, S. Y., Kao, Y. T., Chang, T. T., and Chang, S. T. (2003). Preliminary investigation on the effects of Cinnamomum kanehirae extracts on the mycelial growth of Antrodia camphorata. Quart. J. Chin. Forest 36, 297-306.

Xia, Y. J., Zhang, B. R., Li, W. J., and Xu, G. R. (2011). Changes in volatile compound composition of Antrodia camphorata during solidstate fermentation. J. Sci. Food Agri. 91, 2463-2470. doi: 10.1002/ jsfa.4488

Yu, P. W., Chang, Y. C., Liou, R. F., Lee, T. H., and Tzean, S. S. (2015). Pks63787, a polyketide synthase gene responsible for the biosynthesis of benzenoids in the medicinal mushroom Antrodia cinnamomea. J. Nat. Prod. 79, 1485-1491. doi: 10.1021/acs.jnatprod.5b00798

Zhu, Y., Fang, H. M., Wang, Y. M., Zeng, G. S., Zheng, X. D., and Wang, Y. (2009). Ras1 and Ras2 play antagonistic roles in regulating cellular cAMP level, stationary-phase entry and stress response in Candida albicans. Mol. Microbiol. 74, 862-875. doi: 10.1111/j.1365-2958.2009.06898.x

Conflict of Interest Statement: The authors declare that the research was conducted in the absence of any commercial or financial relationships that could be construed as a potential conflict of interest.

The reviewer VK and handling Editor declared their shared affiliation.

Copyright (c) $2017 \mathrm{Lu}, \mathrm{Zhu}, \mathrm{Li}$, Geng, Shi and Xu. This is an open-access article distributed under the terms of the Creative Commons Attribution License (CC BY). The use, distribution or reproduction in other forums is permitted, provided the original author(s) or licensor are credited and that the original publication in this journal is cited, in accordance with accepted academic practice. No use, distribution or reproduction is permitted which does not comply with these terms. 